\title{
AS TECNOLOGIAS DE CUIDADO DE ENFERMAGEM OBSTÉTRICA FUNDAMENTADAS PELA TEORIA AMBIENTALISTA DE FLORENCE NIGHTINGALE
}

\author{
The Care Technologies of Obstetrical Nursing Based in the \\ Environmental Theories of Florence Nightingale \\ Las Tecnologías de Cuidado de Enfermería Obstétrica \\ Basadas en la Teoría Ambiental ista de Florence Nightingale
}

Priscila de Oliveira Macedo

Iraci dos Santos ${ }^{4}$
Jane Baptista Quitete ${ }^{2}$

Octávio Muniz da Costa Vargens ${ }^{5}$
Eneida Coimbra Lima ${ }^{3}$

\section{Resumo}

Estudo reflexivo que teve como objetivo discutir o conceito Tecnologia de Cuidado de Enfermagem aplicada à saúde da mulher à luz da Teoria Ambientalista de Florence Nightingale. 0 estudo permitiu identificar e discutir os seguintes aspectos: 0 ambiente e o parto, o acompanhante durante o trabalho de parto e parto, a privacidade, o cuidado de enfermagem à mulher durante as modificações fisiológicas, a mulher como protagonista do trabalho de parto e parto, a presença atenciosa da enfermeira no ambiente da mulher, o respeito à individualidade, o ambiente acolhedor, sons e iluminação, a dieta líquida durante o trabalho de parto e parto, a deambulação e movimentação livre durante o trabalho de parto e parto, higiene e confor to, a intersubjetividade na relação enfermeira-usuária e o resgate do saber feminino popular. Concluiu-se que é possível a apropriação dos conceitos da Teoria Ambientalista para fundamentar as Tecnologias de Cuidado aplicadas no cotidiano da Enfermagem Obstétrica.

Palavras-chave: Enfermagem. Saúde da Mulher. Tecnologia. Teoria de Enfermagem.

Abstract

Reflexive study with the purpose to discuss the Care Technologies of Obstetrical Nursing concept applied to the Woman Health in the perspective of Florence Nightingale's Environmental Theory. The study allowed to identify and to discuss the following aspects: the nursing care for woman during the physiologic modifications of childbirth, the woman as protagonist of the labor and childbirth, the respect to the individuality, the privacy, the companion during the labor and childbirth, the homelike atmosphere, the sounds and the twilight, the nurse's kind presence in the woman's atmosphere, the liquid diet during the labor and childbirth, hygiene and comfort, the free movement during the labor and childbirth, the intersubjetivity in the relationship nurse-user, and, the rescue of the popular feminine knowledge. It was concluded that it is possible the appropriation of Nightingale's theory concepts in order to sustain the Care Technologies when applied by the obstetric nursing.

Keywords:

Nursing. Woman's Health. Technology. Nursing Theory.

\section{Resumen}

Estudio reflexivo que tuvo como objetivo discutir el concepto Tecnología de Cuidado de Enfermería aplicada a la salud de la mujer a la luz de la Teoría Ambientalista de Florence Nightingale. El estudio permitió identificar y discutir los siguientes aspectos: el ambiente y el parto, el acompañante durante el trabajo de parto y parto, la privacidad, el cuidado de la enfermería a la mujer en las modificaciones fisiológicas, la mujer como personaje principal de su trabajo de parto y parto, la presencia atenta de la enfermera en el ambiente de la mujer, el respeto a la individualidad, el ambiente acogedor, sonidos y iluminación, la dieta líquida mientras el trabajo de parto y parto, la caminata y movimiento libre mientras el trabajo de parto y parto, limpieza y confort, la intersubjetividad en la relación enfermerausuaria, y el rescate del conocer femenino estimado por el pueblo. Se concluyó que es posible adecuar los conceptos de la Teoría Ambientalista para basar las Tecnologías de Cuidado aplicadas al cotidiano de la enfermería obstétrica.

Palabras clave:

Enfermería. Salud de la Mujer. Tecnología. Teoría de Enfermería.

'Enfermeira Obstétrica da Secretaria Municipal de Saúde-RJ e Ministério da Saúde. Aluna do Programa de Mestrado Acadêmico da Faculdade de Enfermagem (FE) da Universidade do Estado do Rio de Janeiro (UERJ). 'Enfermeira Obstétrica da Secretaria Municipal de Campos dos Goytacazes; Professora da Universidade Estácio de Sá -campus Campos dos Goytacazes - RJ. Aluna do Programa de Mestrado da FE /UERJ. ${ }^{3}$ Enfermeira da Unidade Básica de Saúde de Ipatinga-MG; Professora do Centro Universitário do Leste de Minas Gerais. Aluna do Programa de Mestrado da FE/UERJ. " Enfermeira; Professora Adjunta da FE/UERJ. ${ }^{5}$ Enfermeiro Obstetra. Professor Titular da FE/UERJ; Coordenador do Núcleo de Estudos e Pesquisa Enfermagem, Mulher, Saúde e Sociedade (NEPEN-MUSAS). 


\section{CONSIDERAÇÕES INICIAIS}

Trata-se de um estudo acerca de tecnologias de cuidado de enfermagem obstétrica a partir da teoria ambientalista desenvolvida por Florence Nightingale na segunda metade do século XIX, na Inglaterra.

0 interesse em desenvolver este trabalho surgiu da reflexão das autoras durante o mestrado acadêmico da FE/UERJ. Discutimos os aspectos: tecnologia, cuidado, tecnologias de cuidado e a aplicação e apropriação destes termos como práticas próprias da Enfermagem. Refletimos também sobre a importância de adotarmos uma teoria de enfermagem para fundamentar as nossas práticas diárias visando delimitar as funções reais da Enfermagem e valorizar a profissão. Desta forma, o objetivo deste estudo é: discutir o conceito tecnologia de cuidado de enfermagem obstétrica à luz da teoria ambientalista de Florence Nightingale.

Acreditamos que este texto poderá fundamentar teoricamente a utilização das tecnologias de cuidado pelas enfermeiras e suscitar um debate desta prática com mais propriedade por essas profissionais.

\section{METODOLOGIA}

Trata-se de uma reflexão acerca das idéias de Florence Nightingale contidas no livro "Notas sobre Enfermagem - o que é e o que não é" transpostas para a prática de enfermagem obstétrica que utiliza as tecnologias de cuidado para assistir às mulheres.

Os conhecimentos deixados por Florence Nightingale no livro "Notas sobre Enfermagem - o que é e o que não é" foram utilizados como fonte primária neste estudo. Na teoria ambientalista de Florence Nightingale, a doença é vista como um processo restaurador da saúde, e o papel da enfermeira é equilibrar o meio ambiente para que o paciente possa conservar a sua energia vital para recuperar-se da doença ${ }^{1,2}$.

Nas suas anotações ${ }^{1}$, Florence Nightingale cita os elementos do ambiente que devem ser equilibrados para a recuperação da saúde do paciente: ar puro, claridade, aquecimento, silêncio, limpeza, pontualidade e assistência na oferta da dieta.

$\mathrm{Na}$ análise trabalhamos as tecnologias de cuidado de enfermagem obstétrica. Procurou-se fundamentar teoricamente o cuidado pleno prestado às parturientes através dessas práticas que são utilizadas no dia-a-dia pelas enfermeiras obstétricas. Assim, buscamos uma aproximação de algumas concepções de Florence Nightingale com as tecnologias de cuidado de enfermagem obstétrica.

Alguns autores ${ }^{3,4}$ relacionam as tecnologias de cuidado de enfermagem e a teoria ambientalista na construção de um meio favorável, a fim de conservar a energia vital da parturiente para proporcionar um andamento mais fisiológico do trabalho de parto. Neste texto, consideramos tecnologias de cuidado de enfermagem obstétrica como sendo práticas e atitudes de cuidado fundamentadas no modelo humanístico de assistência que têm como principal característica a não invasão do corpo e da privacidade ${ }^{3,5,6}$.

Julgamos o parto e o nascimento como processos fisiológicos e que podem ser vistos como expressões da saúde emocional e sexual das mulheres. Assim, o uso de tecnologias de cuidados de enfermagem visa proporcionar às mulheres um ambiente propício para que a elas tomem posse do seu trabalho de parto.

Florence Nightingale não entendia a gestação como uma patologia e sugeria que as mulheres dessem à luz em ambientes que não fossem destinados aos doentes ${ }^{1,2}$.

As enfermeiras obstétricas, que cuidam de mulheres utilizando uma abordagem humanista, vêm utilizando as tecnologias de cuidado por acreditarem que o momento do trabalho de parto e parto é restaurador da vida sexual das mulheres e, dentro do contexto hospitalar tecnocrata, como tentativa de amenizar a intensa medicalização utilizada. As enfermeiras concordam com Florence Nightingale que o hospital não é um lugar propício para dar à luz, mesmo quando utilizam estas tecnologias de cuidado, práticas que não são próprias do contexto hospitalar.

0 ambiente hospitalar tecnocrata causa aumento da tensão e desequilíbrio hormonal na mulher durante o seu trabalho de parto ${ }^{4,5,7}$. As tecnologias de cuidado de enfermagem empregadas por enfermeiras obstétricas contribuem para 0 resgate de um trabalho de parto e parto mais fisiológico e menos traumático para a mulher e seu bebêt.

Foram realizadas leituras de fontes secundárias sobre a teoria ambientalista ${ }^{2}$, cuidado humano e de enfermagem ${ }^{8,9}$, tecnologias de cuidado de enfermagem ${ }^{3,4}$, modelos de atenção ao parto ${ }^{5,10,11}$ e direitos sexuais e reprodutivos das mulheres ${ }^{12,13}$ que contribuíram na elaboração desta reflexão.

\section{AS TECNOLOGIAS DE CUIDADO E A TEORIA AMBIENTALISTA DE FLORENCE NIGHTINGALE}

\section{0 cuidado de enfermagem à mulher durante as modificações fisiológicas no parto}

Florence Nightingale preocupava-se com a descaracterização da enfermagem devida à inserção da profissão dentro de um modelo tecnocrata e impessoal.

$A$ arte de enfermagem, como atualmente praticada, parece ter sido criada especialmente para desfazer 0 que Deus determinou que a doença fosse, isto é, um processo restaurador. ${ }^{1: 15}$

0 modelo tecnocrata de assistência à saúde da mulher que foi absorvido pela enfermagem visa medicalizar os processos fisiológicos da vida reprodutiva da mulher ${ }^{5}$. Esse processo de medicalização reflete a ideologia do domínio masculino do corpo feminino e os seus interesses ${ }^{12}$ em detrimento ao respeito do "processo restaurador" que representa cada fase da vida das mulheres. Portanto, respeitar a fisiologia do processo de trabalho de parto e parto é uma tecnologia de cuidado, e Florence Nightingale deixa claro que cabe à enfermeira o cuidado às pessoas durante o seu processo restaurador. Entendemos que a enfermeira obstétrica deve cuidar das mulheres durante o trabalho de parto e parto e não interferir neste processo que deve ser considerado "restaurador" e fisiológico.

Mas quando se conseguir a supressão de toda a dor e de todo o sofrimento, que nos pacientes são sintomas não de sua doença, mas da ausência de um ou de todos 
os elementos acima mencionados, essenciais ao êxito dos processos restauradores da natureza, então saberemos quais sintomas da doença e quais os sofrimentos a ela inerentes. ${ }^{1: 15}$

0 cuidado prestado à mulher pela enfermagem, que utiliza as tecnologias de cuidado, visa dar-lhes poder de decisão e ajudá-la a passar, da melhor forma e sem intervenções desnecessárias, pelos processos naturais. Conforme refletia Florence Nightingale, conheceremos as sensações genuínas do trabalho de parto quando devolvermos o processo às mulheres. Ainda segundo ela, a boa assistência é uma prática naturalmente evidente, enquanto a medicalização é sempre privada de méritos totais:

...o valor exato dos remédios específicos e o tipo de tratamento ainda não estão perfeitamente estabelecidos, enquanto que há experiência universal sobre a enorme importância da boa assistência de enfermagem na determinação das conseqüências da doença. ${ }^{1: 15}$

Afinal, deve haver um motivo real para intervir no processo natural do trabalho de parto ${ }^{10}$. 0 cuidado atencioso em promover que a própria mulher conduza o seu trabalho de parto é uma tecnologia de cuidado ${ }^{6}$. Essa reflexão pode ser apoiada nas idéias de Florence Nightingale, que valoriza mais o cuidado zeloso da enfermagem aos remédios e, conseqüentemente, intervenções tecnocratas.

\section{A mulher como protagonista do seu trabalho de parto e parto}

Florence Nightingale nos mostra que é necessário prestar um cuidado humanizado e que o paciente é um ser dotado de cultura e espiritualidade. Neste sentido, deve ser tratado com dignidade e estimulado a exercer suas potencialidades para a cura:

0 a de uma enfermeira deve ser o conhecimento do que significa um ser humano doente. 0 b é saber como comportar-se com uma pessoa doente. O cé saber que seu paciente é um ser humano enfermo, não um animal:163.

A mulher necessita ser vista como protagonista nos seus processos fisiológicos, não deve ser vitimizada por sua natureza. A satisfação de ser mãe e a liberdade para parir são fatores que ajudam a mulher a passar pelo trabalho de parto, reforçando a importância de devolver para elas o papel central neste processo ${ }^{4}$.

A afirmação "tudo o que o doente puder fazer por si mesmo será melhor que o faça; isto vai significar para ele menos ansiedade ${ }^{1: 46 " ~ n o s ~ r e m e t e ~ a o ~ p r i n c i p a l ~ p r e s s u p o s t o ~}$ do paradigma humanístico de atenção ao parto que é considerar a mulher como sujeito na relação de cuidado ${ }^{5}$. A assistência ao parto deve ser centrada nas necessidades das mulheres, que deverão ter seus direitos à informação e à decisão informada respeitados ${ }^{13}$.

A utilização das tecnologias de cuidado permite que a mulher entenda e participe de forma ativa de todas as modificações do seu corpo. 0 profissional é sujeito do cuidado, a mulher conduz todo o processo e não necessita do outro para fazer por ela.
Florence comenta sobre os prejuízos ocasionados ao paciente pelos descuidos causados pela enfermeira, embora este prefira, muitas vezes, não queixar-se por timidez ou para não desagradar a sua enfermeira.

Em todas as classes sociais existe maior número de pacientes tímidos do que de exigentes, e muitos preferem ter uma noite desagradável, vezes seguidas, a lembrar a enfermeira, a cada noite, de tudo que ela se esqueceu $u^{1: 56}$.

A enfermeira não deve esquecer que as tecnologias de cuidado são uma opção e uma decisão da mulher. Deve-se tomar cuidado para que essas práticas não se tornem impositivas. Pensamos que algumas mulheres podem utilizar-se das tecnologias como barganha pela atenção que lhe foi ofertada. As mulheres devem ser, através de orientações e esclarecimentos, estimuladas a participar ativamente do seu processo, essa é a principal tecnologia de cuidado.

\section{0 respeito à individualidade}

0 raciocínio bloqueia a produção do coquetel hormonal necessário para o parto fisiológico ${ }^{7,11}$. Neste ponto, Florence Nightingale procura evitar esforços ao paciente, respeitando sua individualidade:

...cada ato de pensar decompõe algum tecido nervoso; o fato de se introduzir repentinamente um outro pensamento em um cérebro ainda no processo de destruição do tecido nervoso pelo pensamento anterior significa para ele um novo esforço. ${ }^{1: 58}$

A mulher em trabalho de parto utiliza seu cérebro primal para viver o processo de forma fisiológica ${ }^{11}$. Os fatores ambientais próprios dos hospitais são inibidores do trabalho de parto $4,7,11$. No pré-parto ou mesmo durante o período expulsivo, a mulher é perturbada pelos profissionais que pretendem conduzir a expulsão do feto no seu próprio tempo, muitas vezes com a desculpa do término do "sofrimento" que este processo ocasiona.

As tecnologias de cuidado de enfermagem são aquelas atitudes que permitem à mulher viver o seu processo de forma natural, sem a invasão de fatores estressantes ou pensamentos racionais ou sentimentos ruins, que significam um grande esforço.

A irresolução é o que mais transtorna os enfermos... Se propuser ao doente determinado lugar para mudar de ares e logo após sugerir outro, em cada caso, ele cria imediatamente a imagem do dono do lugar, transformando a premissa em idéias, e você terá Ihe causado tanto cansaço ao deslocar sua imaginação de um fato para outro, quanto se realmente o tivesse levado a ambos ${ }^{1: 62}$.

Durante o trabalho de parto, percebemos que diferentes profissionais sugerem variadas formas de "ajudar" a mulher em trabalho de parto. Uns sugerem que ela caminhe um pouco, outros que permaneça no leito em decúbito lateral esquerdo e outros ainda que pare de gritar. A mulher precisa conhecer todos os modelos de assistência obstétrica, suas vantagens e desvantagens, riscos e benefícios e precisa ser tratada como 
sujeito da situação. Na verdade o que ela necessita é que o seu direito à informação e à decisão informada seja respeitado ${ }^{13}$.

\section{A privacidade}

Na prática percebemos que há momentos, em especial durante o trabalho de parto e parto, em que a mulher necessita de silêncio e introspecção. Ela fecha os olhos, emite sons, balança o corpo, e essas atitudes muitas vezes são interrompidas pelos profissionais que a cercam. Alguns deles não consideram estas manifestações como necessárias e benéficas ao trabalho de parto. Refletimos que essas atitudes das mulheres, preparando-se para o parto, poderiam ser comparadas a diversos momentos cotidianos que necessitam de silêncio e introspecção, como a oração, o estudo e o sono. Neste sentido, Florence Nightingale discute a interferência das pessoas presentes no ambiente sobre as necessidades dos pacientes:

Uma lavadeira estranha ao serviço pode passar tarde da noite pela enfermaria a fim de recolher as "coisas" e por engano entrar no quarto do doente justamente quando acaba de adormecer, causando-Ihe um grande choque, de efeitos irremediáveis, embora ele mesmo ache graça na ocorrência e provavelmente nunca a mencione. ${ }^{1: 44}$

A observação dos profissionais interrompe a atitude instintiva da mulher, impedindo a liberação dos hormônios próprios de trabalho de parto e conseqüentemente prejudicando o andamento natural deste processo e contribuindo para o aumento da dor. ${ }^{4}$

0 respeito ao direito da mulher à privacidade no local do parto é uma prática demonstradamente útil e que deve ser estimulada pelos profissionais de saúde ${ }^{10}$. Permitir 0 comportamento instintivo da mulher é uma tecnologia de cuidado, e Florence Nightingale respeitava a privacidade, o tempo e o ritmo das pessoas.

\section{0 acompanhante durante 0 trabalho de parto e o parto}

Durante o trabalho de parto, percebemos que a maioria das mulheres deseja estar acompanhada por pessoas que lhe sejam familiares. A mulher acompanhada fica mais tranqüila, sente-se mais segura. Muitas vezes, ao abordar algumas mulheres sem acompanhantes, elas expressam medo por estarem sozinhas. Florence Nightingale mostrava-se cuidadosa quanto à presença do acompanhante:

... a entrada de visitante cuja presença seria muito importante pode ser impedida, enquanto se permite a presença de alguém cuja ausência seria da maior importância - isto porque a pessoa responsável pelo enfermo nunca fez a si própria a pergunta: "Que é feito quando não estou presente? 1:45

A parturiente deve estar acompanhada por uma pessoa de sua escolha. Por diversos motivos, alguns acompanhante não estão presentes ou não têm habilidades para lidar com a situação de trabalho de parto e parto. Os profissionais que cercam a mulher deveriam ser capazes de realizar, além de suas atribuições técnicas, o apoio necessário para aquele momento ${ }^{10}$, através da intersubjetividade na relação do cuidado e orientações aos acompanhantes.

Incentivar a presença de um acompanhante é uma prática demonstradamente útil e que deve ser estimulada no plano individual de parto ${ }^{10}$. A enfermeira deveria se preocupar com a presença ou ausência da pessoa de escolha da parturiente. 0 apoio e a segurança transmitida pela pessoa de confiança da parturiente é uma tecnologia de cuidado, e Florence Nightingale se preocupava com a presença e/ou ausência de pessoas que poderiam ser úteis ou não para a pessoa que estava sob seus cuidados.

\section{0 ambiente acolhedor}

Florence Nightingale discute a importância da variedade dos ambientes para aliviar a tesão dos pacientes:

É incompreensível para qualquer pessoa, a não ser para a enfermeira experimentada ou para o paciente antigo, o grau de sofrimento que os nervos do enfermo suportam ao olhar para as mesmas paredes, o mesmo teto, o mesmo ambiente... 1:67

Percebemos que é agradável para a mulher, durante o trabalho de parto, conhecer o ambiente no qual está inserida. Portanto, toda a unidade, inclusive as enfermarias e até mesmo a parte externa, onde ela pode tomar banho de sol, devem Ihe ser apresentados. As mulheres parecem mais tranqüilas e freqüentemente relatam melhora da dor quando deambulam pela unidade. Acreditamos que a existência de outros ambientes dentro da maternidade, como salas de relaxamento, seja um grande alívio para a mulher que não se sente doente, dentro de um hospital tradicional. A autora continua justificando suas idéias:

Raras vezes é devidamente valorizado o efeito das bonitas peças artísticas... do esplendor das cores, sobre as doenças ${ }^{1: 67}$.

...Apesar do pouco que sabemos sobre como somos afetados pelas formas, cores e pela luz, de uma coisa temos conhecimento: esses fatores exercem um real efeito sobre o físico ${ }^{1: 68}$.

... Desejaria... que se pensasse um pouco mais sobre o efeito do corpo sobre a mente...não tem idéia de como a ansiedade é aliviada; não tem idéia também de como é intensificada nas pessoas que não podem variar de atividades... 1:69.

0 ambiente acolhedor visa aproximar ao máximo o ambiente muitas vezes impessoal das maternidades ao ambiente doméstico da parturiente. Acredita-se que desta forma será reduzido o nível de estresse causado, o que irá favorecer o desenrolar fisiológico do trabalho de parto. Também existem estudos que abordam a cromoterapia como uma tecnologia de cuidado ${ }^{4,10}$.

\section{Os sons}

Para Florence Nightingale, a qualidade dos sons é mais prejudicial ao doente do que sua intensidade:

... a intensidade do barulho e seu efeito sobre o próprio órgão da audição raramente afetam o doente. Ele pode suportar, por exemplo, a colocação de um andaime perto 
da casa, mas não suporta conversas, menos ainda cochichos fora do quarto, especialmente se de uma voz familiar ${ }^{1: 52}$.

A mulher em trabalho de parto deve desativar o seu córtex e ativar o cérebro primitivo para que haja o equilíbrio hormonal necessário. 0 ruído é um fator que ativa o córtex cerebral, inibindo o trabalho de parto $0^{4,7,11}$.

Os ruídos externos, em especial as vozes de comando durante o trabalho de parto, não ajudam a mulher. Assim, puxos e movimentos respiratórios dirigidos tiram a autonomia da mulher. Deixar a mulher seguir seus instintos e manter um ambiente silencioso é uma tecnologia de cuidado de enfermagem.

\section{A penumbra}

0 brilho das luzes artificiais dos hospitais também excita 0 córtex cerebral da mulher em trabalho de parto ${ }^{7}$. Sobre a penumbra e o contato direto com a luz restauradora do sol, Nightingale afirma que:

E não é apenas a claridade que desejam, mas a luz solar direta ${ }^{1: 96}$.

Desnecessário acrescentar que há casos agudos..., para os quais a penumbra é necessária. Um quarto escuro, porém, é inadmissível mesmo nesses casos ${ }^{1: 98}$.

Leboyer $^{14}$ acredita que a penumbra aguce a nossa sensibilidade. A penumbra também tem influência definitiva na prevenção de lesões oculares no bebê e um efeito não estressante para o ser que acaba de ter seu primeiro contato visual com a luz.

Interessante reparar que o importante não é a intensidade da luz, porém sua qualidade. A luz do sol provavelmente não interfere no córtex materno, pelo contrário, parece que as mulheres se sentem confortáveis durante este contato. Por outro lado, as luzes artificiais inibem o córtex primal e a penumbra o estimula ${ }^{7,11}$. Parece que a natureza inibe 0 neocórtex, enquanto um ambiente artificial o estimula. Assim, manter um ambiente o mais natural possível é uma tecnologia de cuidado e Florence Nightingale trabalha muito neste sentido.

\section{A presença atenciosa da enfermeira no ambiente da mulher}

A presença atenciosa da enfermeira é um fator de grande auxílio durante o trabalho de parto ${ }^{4}$. Neste sentido, Florence Nightingale descreve a relevância da postura da enfermeira quando trata seus pacientes:

Sente-se sempre onde o doente possa vê-lo... Se você torna esse ato cansativo para o doente, prejudica-o e muito. Também manter-se de pé por muito tempo obriga-o a levantar continuamente os olhos para enxergá-lo 1:57.

Não fale com um doente às suas costas, nem da porta, à distância, ou quando ele estiver ocupado com alguma coisa ${ }^{1: 57}$.

Quando a mulher atinge um bom equilíbrio hormonal e chega ao período expulsivo, parece estar em outro mundo, repetindo apenas palavras simples ${ }^{10}$. Estar junto com uma mulher em trabalho de parto é uma tecnologia de cuidado ${ }^{3}$.

A mulher necessita da companhia de uma pessoa que the transmita segurança neste momento. A simples presença atenciosa, a comunicação não verbal e o toque são suficientes para a mulher em trabalho de parto e parto. Independente da presença do acompanhante, a enfermeira exercita sua escuta sensível implementando seu cuidado, experienciando a situação, sendo/estando presente por inteiro, valorizando a intimidade, 0 acolhimento, a sintonia ${ }^{8,9,14}$.

\section{A dieta líquida durante o trabalho de parto}

No dia-a-dia de atividades como enfermeiras obstétricas percebemos que, se não todas, quase todas as mulheres desejam ingerir alguma coisa, ao menos um pouco de água. Sobre a dieta dos pacientes, Florence Nightingale diz que:

...milhares de enfermos anualmente sofrem fome no meio da maior abundância, apenas devido à falta de atenção às únicas maneiras que tornam possível sua alimentação. Essa falta de atenção é impressionante tanto em relação às pessoas que insistem para que os doentes façam o que lhes é totalmente impossível, quanto aos próprios doentes que se recusam a fazer um esforço perfeitamente possível ${ }^{1: 73}$.

No trabalho de parto fisiológico, natural, é seguro que a mulher se alimente conforme seus desejos ${ }^{10}$. Podem ser oferecidos pequenos tabletes de chocolate a cada duas horas ou volumes de 150 mililitros de líquidos adocicados quando 0 intervalo para o parto for maior do que duas horas ${ }^{15}$.

A alimentação durante o trabalho de parto é uma tecnologia de cuidado já que a fome e a sede acarretam grande desconforto e risco para a mulheres e bebês, aliás para todo ser humano. 0 trabalho de parto requer enormes quantidades de energia, e como não podemos antever sua duração, devemos repor as fontes de energia, sobretudo a ingesta hídrica e de glicose via oral ${ }^{10}$. 0 que infelizmente acontece nas maternidades tecnocráticas é a reposição de fluidos e glicose por via endovenosa, isto restringe a mulher ao leito e gera mais intervenções desnecessárias.

\section{Higiene e conforto}

Aprendemos desde a graduação que medidas de higiene e conforto são práticas próprias da enfermagem e que são de grande valia para os pacientes, Florence Nightingale reforça esses conhecimentos quando diz que:

...um adulto sadio exala pelos pulmões e pela pele, durante as vinte e quatro horas do dia, cerca de um litro e meio de umidade carregada de matéria orgânica pronta para entrar em putrefação, e durante a enfermidade essa quantidade fica muito aumentada e a qualidade é sempre mais nociva, pergunte-se: aonde vai toda essa umidade? Vai principalmente para as roupas de cama... ${ }^{1: 91}$.

Considerando que as mulheres durante o trabalho de parto e parto apresentam perdas transvaginais, aumento da exalação pelos pulmões e pela pele e têm a necessidade de urinar e evacuar, torna-se ímpar a necessidade de mantê-las confortáveis, 
com roupas limpas, com liberdade para ir banhar-se ou usar o sanitário se desejarem. 0 ambiente hospitalar dita regras tais como: confinamento no leito ou proibição de entrar na instituição com seus pertences de higiene. Tudo isto contribui para que a mulher se sinta desconfortável durante esse período.

A manutenção da higiene composta por banhos, a higiene oral e a troca de roupas freqüentes são medidas que reforçam a auto-estima da mulher, favorecem o confor to e promovem os benefícios da água durante este processo $0^{3,411}$. Medidas como enema e tricotomia são consideradas desnecessárias. Estas medidas não reduzem a contaminaçã $0^{10}$, portanto não devem ser consideradas medidas de higiene. Florence traz ainda outras contribuições:

\section{...pois se deixarem os enfermos sem banho ou com as roupas saturadas da perspiração ou de outras secreções estarão interferindo danosamente nos processos naturais da saúde e tão efetivamente quanto se ministrassem ao paciente uma dose de veneno de ação demorada, por via orall:106.}

Portanto, a higiene também é uma tecnologia de cuidado quando promove conforto e ajuda a mulher a percorrer seu processo de trabalho de parto. A higiene permite que a mulher tenha contato com a água, que é um elemento importante para este momento. Florence Nightingale se preocupava com a nocividade do acúmulo destas excretas dos pacientes sobre suas vestimentas e considerava a higiene um importante cuidado de enfermagem.

\section{A deambulação e movimentação livre durante o trabalho de parto}

Percebemos que as mulheres em trabalho de parto confinadas ao leito mostram-se muito agitadas. Neste sentido, Florence Nightingale afirma que: supõe-se geralmente que a agitação seja um sintoma de febre - nove entre dez casos é um sintoma de confinamento no leito. ${ }^{1: 90}$

Muitos autores ${ }^{3,4,11,15}$ são unânimes quando se trata dos benefícios da posição vertical no primeiro estágio do trabalho parto. A posição vertical e a movimentação melhoram o fluxo sangüíneo fetal, aumentam a intensidade e eficácia das contrações, reduzem a dor, contribuem para a introspecção necessária para o andamento fisiológico do processo e facilitam a ação da gravidade.

A liberdade para movimentar-se durante o trabalho de parto é uma tecnologia de cuidado essencial para o bom andamento do trabalho de parto ${ }^{3,6}$, e Florence Nightingale discutia acerca dos malefícios ocasionados ao paciente confinado ao leito.

\section{A intersubjetividade na relação enfermeira-usuária}

Florence Nightingale discute a relação enfermeira-paciente, a necessidade de conhecer os pacientes, saber identificar os problemas e ainda ser ponto de referência para eles:

...a enfermeira deve ser uma pessoa com a qual se possa contar... não deve bisbilhotar, nem falar sem necessidade...deve ser rigorosamente sóbria e honesta...religiosa e devotada; deve respeitar sua própria vocação porque a vida, a mais preciosa dádiva de Deus, é posta literalmente em suas mãos; deve ser uma observadora minuciosa, fiel, rápida; uma pessoa de sentimentos delicados e recatados ${ }^{1: 168}$.

A intersubjetividade da relação está na essência do cuidado humano que se revela pela atitude de ocupação, de preocupação, de responsabilização e de envolvimento afetivo com o outro ${ }^{8}$.

Apreensão, incerteza, espera, expectativa e medo de surpresa prejudicam mais o doente do que qualquer esforço físico ${ }^{1: 46}$.

A mulher como protagonista do seu processo deve ser mantida informada sobre tudo que está acontecendo com o seu corpo. Ela deve ser encorajada a participar do seu processo, tocando-se, por exemplo.

... diga sempre ao doente, antes de deixá-lo, a hora em que vai sair e quando vai voltar...:46.

Considerando a importância dos profissionais que cercam a mulher neste processo, é tecnologia de cuidado que a mulher conheça os profissionais que cuidam dela e tenha a garantia da continuidade da assistência quando acabar o turno.

\section{A lição prática mais importante que pode ser dada a enfermeiras é ensinar-lhes o que observar, como observar, os sintomas que indicam melhoria no estado do doente, os que indicam o contrário, quais são os de importância, os de nenhuma importância... ${ }^{1: 119}$.}

Saber observar o comportamento das mulheres é uma tecnologia de cuidado. Uma observação acerca das expressões verbais e não verbais da parturiente mostra para a enfermeira os medos, expectativas e até a evolução do parto. Quando está livre, a mulher deambula e não consegue sentar-se em período expulsivo, por exemplo. Ela tem necessidade de agarrar algo ou dobrar os joelhos ${ }^{11}$, não é necessário realizar um toque para se ter certeza que o período expulsivo começou.

... ainda que inquestionavelmente exista uma fisionomia da doença tanto quanto da saúde, de todas as partes do corpo humano, o rosto talvez seja a que menos indícios demonstra ao observador comum ou ao visitante casual. Porque, dentre todas as partes do corpo, é a mais exposta a outras influências, além da saúde ${ }^{1: 129}$.

Para utilizar tecnologias de cuidados, a enfermeira precisa conhecer as suas clientes, reconhecer o que é manifestação do processo fisiológico e o que é expressão do processo sócio-cultural. Manter a cliente/família orientada, esclarecida, livre de medos e mitos e, finalmente, empoderada é tecnologia de cuidado.

...a enfermeira deve compreender..., toda a mudança de fisionomia de seu paciente, toda a mudança em suas atitudes, toda a mudança em sua voz. Deve estudálas até que se sinta segura de que ninguém mais as compreende tão bem quanto ela própria ${ }^{1: 162}$.

0 olhar e a fisionomia implicam relação, lugar onde não se torna possível ser indiferente. É na acolhida ou na rejeição, na aliança ou na hostilidade para com o rosto do outro que se estabelecem as relações mais primárias do ser humano, e se decidem as tendências de dominação ou de cooperação ${ }^{8}$.

A enfermeira deve fazer distinção entre as idiossincrasias dos pacientes. Um gosta de sofrer 
sozinho, de ser o menos auxiliado possível. 0 outro prefere ser objeto de preocupação constante, de piedade e gosta de ter sempre alguém com ele. Ambas essas peculiaridades devem ser observadas e satisfeitas mais do que o são atualmente $e^{1: 130}$

0 importante é respeitar as vontades individuais das parturientes. As tecnologias de cuidados são ditas não invasivas porque oferecem às mulheres o direito de se utilizarem delas ou não. Assim, algumas mulheres sentem-se bem na companhia constante do profissional, outras preferem ficar isoladas e deitadas. Umas ingerem alimentos, enquanto outras preferem o jejum, e daí por diante.

\section{0 resgate do saber feminino popular}

Florence Nightingale valoriza o saber feminino, porém submisso ao saber médico, masculino. Hoje, sabemos que o conhecimento feminino subsidia nossa prática, porém, numa nova perspectiva, ou seja, do cuidado humanizado e baseado em evidências científicas:

Seria um grande auxilio, ao invés de obstáculo, se os médicos soubessem fazer com que as enfermeiras obedecessem às suas ordens. Esse preparo das mulheres diminuiria o trabalho do médico... ${ }^{1: 145}$.

A característica não invasiva das tecnologias de cuidado de enfermagem tem sua origem no conhecimento adquirido e passado pelas mulheres através de gerações ${ }^{3}$. A menstruação, anticoncepção, gravidez, parto, etc, sempre foram assuntos discutidos e resolvidos pelas mulheres. As parteiras eram, e ainda são em alguns locais do país, a referência para muitas mulheres. Assim, a arte de cuidar estaria imersa em significados intuitivos e emotivos ${ }^{9}$. Infelizmente, em decorrência da medicalização e do controle do corpo da mulher pelos homens, as mulheres foram alienadas sobre si mesmas ${ }^{12,13}$.

... a medicina é a cirurgia das funções... Nenhuma delas pode fazer alguma coisa a não ser a remoção de obstruções; nenhuma delas pode curar; só a natureza

\section{Referências}

1. Nightingale F. Notas sobre enfermagem: o que é e o que não é. Tradução Amália Correa de Carvalho. São Paulo (SP): Cortez; 1989.

2. Lobo ML. Florence Nightingale. In: George JB, organizadora. Teorias de enfermagem: os fundamentos à prática profissional. Porto Alegre (RS): Artes Médicas; 2000.

3. Medina ET. Tecnologias de cuidado de enfermagem obstétrica e seus efeitos sobre o trabalho de parto: um estudo exploratório [dissertação de mestrado]. Rio de Janeiro (RJ): Faculdade de Enfermagem/UERJ; 2003.

4. Macedo PO, Progianti JM, Vargens OMC, Santos VLC, Silva CA. Percepção da dor pela mulher no pré-parto: a influência do ambiente. Rev Enferm UERJ 2005; 13: 306-12.

5. Davis-Floyd R. The tecnocratic, humanistic and holistic paradigms of childbirth. Intern J Gynecol \& Obstetr 2001; 75(S5-S23).

6. Progianti JM, Vargens OMC. As enfermeiras obstétricas frente ao uso de tecnologia não invasiva de cuidado como estratégia na desmedicalização do parto. Esc Anna Nery Rev Enferm 2004 ago; 8(2): 194-97. pode curar... ,e o que a enfermagem tem de fazer em ambos os casos é manter o paciente nas melhores condições possíveis, a fim de que a natureza possa atuar sobre ele. ${ }^{1: 146}$

0 objetivo do uso das tecnologias de cuidado é que a própria mulher conduza o seu trabalho de parto. Ela é o sujeito do seu processo, sendo a enfermeira sujeito do cuidar através das tecnologias de cuidado.

\section{CONSIDERAÇÕES FINAIS}

Esse estudo abordou as principais tecnologias empregadas na assistência de enfermagem à mulher durante o seu trabalho de parto e parto.

Ao realizar esta análise constatamos que é possível aplicar as bases teórico-filosóficas da teoria ambientalista de Florence Nightingale aos pressupostos das tecnologias não invasivas de cuidado de enfermagem obstétrica.

0 trabalho também permitiu a apropriação de conceitos fundamentais para o cotidiano da enfermagem, através de uma leitura sensível dos escritos da precursora de nossa profissão.

Consideramo-nos satisfeitos com a realização deste estudo, pois o mesmo nos permitiu refletir acerca da nossa prática diária à luz da teoria ambientalista. Isto nos ajudou a cristalizar a idéia das tecnologias não invasivas como uma prática própria da enfermagem obstétrica.

Acreditamos que o objetivo deste estudo foi respondido, uma vez que o uso das tecnologias de cuidado de enfermagem obstétrica colabora para o equilíbrio ambiental ideal para a mulher durante o momento da parturição. Assim, o conceito não invasão do corpo e da privacidade é respeitado, permitindo que o parto aconteça de forma fisiológica.

Julgamos necessária a realização de outros estudos a respeito desta temática que possam fornecer cada vez mais subsídios para o construto teórico da prática da enfermagem obstétrica brasileira.

7. Odent M. A cientificação do amor. $2^{\mathrm{a}}$ ed. Florianópolis (SC): Saint Germain; 2002.

8. Boff L. Saber cuidar: ética do humano: compaixão pela terra. $10^{\mathrm{a}}$ ed. Petrópolis (RJ): Vozes; 2004.

9. Neves EP. As dimensões do cuidar em enfermagem: concepções teóricofilosóficas. Esc Anna Nery Rev Enferm 2002, dez; 6 (1): 79-92.

10. Organização Mundial da Saúde- OMS. Maternidade segura: assistência ao parto normal: um guia prático. Relatório de um grupo técnico. Genebra; 1996.

11. Odent M. 0 renascimento do parto. $1^{\text {a }}$ ed. Florianópolis (SC): Saint Germain; 2002.

12. Vieira EM. A medicalização do corpo feminino. Rio de Janeiro (RJ): FIOCRUZ; 2002.

13. Rede Nacional Feminista de Saúde. Direitos Sexuais e Direitos Reprodutivos. Dossiê Humanização do Parto. São Paulo (SP); 2002. 14. Leboyer Frédérick. Nascer sorrindo. $14^{\mathrm{a}}$ ed. São Paulo (SP): Brasiliense; 2004.

15. Neme Bussâmara. Obstetrícia básica. $2^{a}$ ed. São Paulo (SP): Sarvier;2000.

Recebido em 07/05/2007 Reapresentado em 20/09/2007 Aprovado em 01/10/2007 